\title{
A study of the impacts of existing artificial optical radiation at student housing sites
}

\author{
P. Hebert \\ Oklahoma State University, USA
}

\begin{abstract}
Visible optical radiation in the housing sector accounts for $17 \%$ of the total energy consumed in the USA. Recommendations encourage the use of sustainable lighting to reduce energy consumption, but all stakeholders have not complied. Some existing installations provide high light levels, use inefficient lighting, and waste resources. Over-illuminated sites create light pollution and "light trespass," which may upset circadian rhythms and damage health. Some housing sites utilize short-lived light sources, which must be replaced often, sending solid waste to landfills. The invisible effects of artificial optical radiation, such as those from ultraviolet light (UV), may have adverse environmental and health impacts. In this study, researchers explored the quantitative aspects of artificial optical radiation found at five university student housing sites. They integrated technical literature and lighting industry recommendations with previous studies and new field measurements to raise awareness of environmental impacts and to ultimately encourage informed choices of sustainable lighting at student housing sites. The researchers led undergraduate students in night-time field studies to measure and document existing lighting conditions. They utilized various hand-held devices to measure and analyze visible light, UV light, and sky quality. Artificial optical radiation from various sources was in evidence at all sites. A review of the published standards revealed some of sites' artificial light levels exceeded recommendations. Light pollution and light trespass were found. Sky quality was fair to poor. The environmental impact of UV radiation in the current study was found to be negligible. However, other measurable impacts produced by nonsustainable lighting sources, including wasted light, light pollution, and light trespass, are of concern to the environment and to housing stakeholders.
\end{abstract}

Keywords: environmental impact, housing, lighting, pollution, sustainability. 


\section{Introduction}

\subsection{Background}

Visible optical radiation used in the housing sector accounts for $17 \%$ of the total energy consumed in the United States of America [1]. Adherence to recommended illumination levels can support safety and security and reduce energy consumption when efficient light sources are used, but not all stakeholders have complied. Some sites may utilize non-sustainable and inefficient lighting that wastes resources. Over-illuminated sites create light pollution and "light trespass," which may upset circadian rhythms and damage health. Some sites may utilize short-lived light sources, which must be replaced often, sending solid waste to landfills. The invisible effects of artificial optical radiation, such as those from ultraviolet (UV) light may have adverse environmental and health impacts.

\subsection{Purpose}

In this study, researchers explored quantitative aspects of artificial (electric) optical radiation at five university student housing sites on two campuses in the mid-western USA as part of a larger federally funded project. Students participated with faculty on research teams in a national competition designed to provide sustainability education. The researchers integrated technical literature and industry recommendations with previous studies and new field measurements, in order to raise awareness and ultimately to encourage informed choices of sustainable lighting at student housing sites.

\section{Literature review}

Optical radiation is complex and influences physiological and behavioral responses. Although optical radiation is often associated with positive outcomes, some negative aspects are also associated. Light pollution is defined as "the scattering of electric light into the atmosphere, usually caused by luminous flux above the horizontal" [2]. Light trespass is defined as "light that strays from its intended purpose, causing visual annoyance" [2]. Artificial light from unshielded and poorly located sources may enter buildings through fenestration, disturb slumber, disrupt circadian rhythms, or otherwise negatively influence health. Light fixtures that do not produce any light above the horizontal are known as "cutoff" fixtures [3]. The Illuminating Engineering Society of North America (IESNA) - an organization that publishes lighting-related research, as well as recommend levels of optical radiation for particular visual tasks - recently emphasized the profound effect of light on human health and the importance of studying dark/light cycles [4]. Although the exact light levels required to impact human circadian rhythms are as yet unknown, several studies involving light and circadian rhythm were found [5-8]. Boyce [9] and Figueiro et al. [10], among others, have called for the continued study of light and circadian rhythms, while 
Figueiro et al. [10] expressed concern about the possible link between night-time exposure to artificial light and increased cancer risk.

Although it has long been understood that artificial optical radiation has both health benefits and risks [4], humans have increasingly illuminated their world [11]. Some have identified aesthetic, safety, and security issues as reasons for illumination. However, others perceive artificial lighting as a disruption of the natural dark/light cycle and a waste of energy. Rich and Longcore [12] have written about the negative environmental effects of lighting, including those on various species. In 2009, the American Medical Association (AMA) released a mandate supporting sustainable lighting, waste reduction, and light pollution reduction [13]. Additional researchers have studied non-visible light and its health implications [14-19]. Other lighting studies focused on consumers in retail settings [20-22]. Consumers' intentions were explored by Kalifatis et al. in a conceptual model of consumers' intentions to adopt environmentally friendly products [23]. Few scientific studies have been published regarding sustainable lighting and energy consumption implications in the USA [24-26]. However, research precedence was found for the utilization of questionnaires to assess the awareness, knowledge, experience, or intentions of participants regarding sustainable lighting [25]. Also, several studies were found regarding the utilization of energy efficient (higher efficacy and longer lived) lighting sources, Light Emitting Diodes (LEDs) or Compact Fluorescent Lighting (CFLs), outside of the USA [27-31]. Consumers' attitudes towards LEDs, CFLs and incandescent were examined by Stall-Meadows and Hebert [24] in empirical field research set in museums; this study also utilized student researchers. Other lighting field studies were found [20, 22, 32]. Programs such as EnergySTAR [33] encourage energy-saving lighting, and others have gathered topical market research [34, 35]. CEE cited inadequate consumer education as a barrier to the adoption of CFLs [1]. No previous studies quantifying optical radiation at housing sites or involving students in housing field study data collection were found.

The current exploratory study utilized concepts from Sherri Arnstein's classic theoretical work, "A Ladder of Citizen Participation" [36]. Arnstein encouraged "citizen" stakeholders to facilitate decision making processes made by societies, including those relative to planning and design. She devised an eight-rung ladder model, divided into three groups of rungs, ascending toward more participatory practices. The lowest group she identified as "nonparticipation," which included "manipulation" and "therapy." The middle group she labelled "tokenism," which included "informing," consultation," and "placation." The top group she called "citizen power," which included "partnership," "delegated power," and the top rung, "citizen control." By involving student stakeholders, the current study endeavours to fill a gap in the existing literature regarding the impacts of nonsustainable artificial optical radiation. According to Attardi, "to create a future of growth and sustainability should be our message ... Educating the general public on lighting is ... a very good idea" [37]. He proposed a model to explain consumer behavior relative to sustainable lighting. He claimed that awareness of new lighting technologies led to acceptance, which led to preference [37]. In the 
current exploratory study, both Arnstein's and Attardi's theoretical works were applied by engaging students in an investigation of the effects of optical radiation at university housing sites.

\section{Methodology}

In the current study, three research hypotheses were proposed and tested:

$H_{1}$ : Artificial optical radiation at housing sites will exceed recommendations.

$\mathrm{H}_{2}$ : Non-sustainable light sources will be identified at student housing sites.

$\mathrm{H}_{3}$ : Artificial optical radiation will be found on housing units'fenestration.

The researchers selected a convenience sample of five student housing sites located at two college campuses in the mid-western USA. During three months of the research period, October 4 to November 1, 2010, sixty-six undergraduate university students, four graduate students, and three faculty members participated in one or more of five site visits. The weather and moon phases for each of the sites during the study period was obtained from official sources.

Using IESNA nomenclature, each site was classified as having either "bright surroundings" or "dark surroundings" [38], based on the ambient visual illumination proximal to each housing site. The current researchers also classified the sites' predominant vertical surfaces' reflectance values using IESNA terms: "light," "medium light," "medium dark," or "dark" [38]. To determine reflectances, the researchers compared building surfaces to paint chips and corresponding light reflectance values (LRVs) published in paint manufacturers' fan decks (Imperial Chemical Industries Paints and PPG Pittsburgh Paints). Through visual inspection, the researchers determined which paint chips most closely matched the field sites' exterior buildings' surfaces. The corresponding LRVs were noted. The two digits of the LRV corresponded to the percentage of light reflected. A surface with an LRV of 75 reflected $75 \%$ of the light falling upon it. For the purposes of this study, "light" surfaces were those with an LRV of 75-99, "medium light" surfaces were 50-74, "medium dark" surfaces were 25-49, and "dark" surfaces were 24 or less. Additionally, the research team utilized spectral distribution identification cards with diffraction gratings to distinguish observed light sources as incandescent, fluorescent, mercury, metal halide, sodium, or neon.

At each site, the researchers field-selected ground floor housing units with windows. The researchers examined the sties' existing lighting fixtures, noted their overall styles, and determined if they were "cutoff" or "non-cutoff" through visual inspection. They used masking tape to prepare temporary measurement grids on horizontal surfaces (on-grade landscape and paving adjacent to housing units) and vertical surfaces (housing units' exterior walls, and windows), fig 1. This facilitated the measurement of optical radiation at regular intervals.

Beginning at 19:30 hours on five separate evenings, researchers examined and measured the artificial optical radiation falling on vertical and horizontal planes. This information was recorded on field data sheets, plans, and sketches. The research team measured visible light in footcandles (fc) and lux (lx) with a GTE Sylvania DS-2000 meter at selected housing units. At these identical 


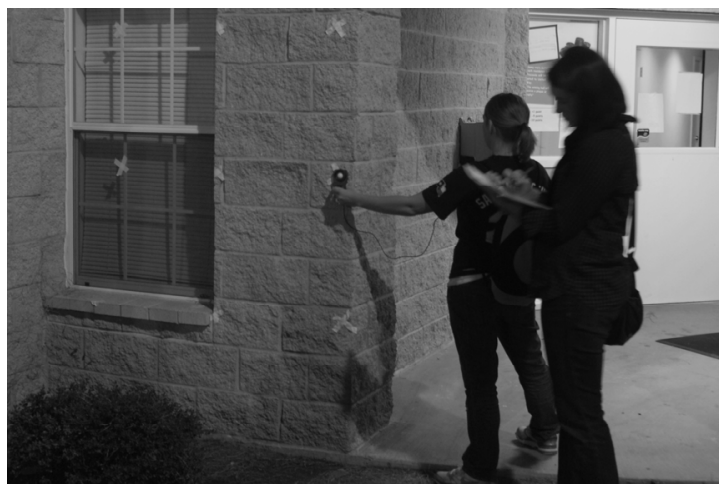

Figure 1: $\quad$ Measurement grid.

locations, UV radiation was also measured in microwatts $/ \mathrm{cm}^{2}$ with a Mannix UV-340 meter, which measured UVA and UVB in the $290 \mathrm{~nm}$ to $390 \mathrm{~nm}$ range. Overall sky quality measurements were taken at each site, determined in magnitudes per square arcsecond, using a Unihedron Sky Quality meter, SQM-L. A higher sky quality reading indicated a lower level of light pollution. For example, a reading of 21 would indicate a very dark sky, while a reading of 16 would indicate a light polluted sky [39]. Researchers also documented sites and field research activities with digital cameras. From November, 2010, through March, 2011, researchers transferred data from field sheets, coded the data, compared field measurements to IESNA and IDA recommendations, and analyzed findings.

\section{Results}

The majority of the sites, Sites A, B, C, and D, experienced clear skies during field study visits. However, one of the sites, Site E, was "mostly cloudy." The temperatures ranged from a low of $45^{\circ} \mathrm{F}\left(7^{\circ} \mathrm{C}\right)$ at Site $\mathrm{E}$ to a high of $73^{\circ} \mathrm{F}\left(23^{\circ} \mathrm{C}\right)$ at Site $\mathrm{C}$. None of the sites experienced any precipitation during the field visits. The moon phases varied from Waning Crescent to Full Moon. Sky quality measurements across student housing sites ranged from a minimum of $10.8 \mathrm{mags} /$ arcsecond $^{2}$ at Site D to a maximum of 16.3 mags/arcsecond ${ }^{2}$ at Site E. Therefore, sky quality was categorized as poor to fair, with evidence of light pollution found at all five sites. Exterior lighting fixtures were categorized by the researchers through visual inspection, fig 2. Only Sites $\mathrm{C}$ and $\mathrm{E}$ utilized cutoff fixtures exclusively, as shown in Table 1.

A total of 149 spectral distribution identifications were made by the researchers. The light source most often identified across all sites was fluorescent $(n=50,33.56 \%)$. The second most identified was incandescent $(n=39$, $26.17 \%)$. The third most identified was metal halide $(n=26,17.45 \%)$. The least identified light sources included: sodium $(n=15,10.07 \%)$, mercury $(n=12$, $7.94 \%)$ and neon $(n=7,4.70 \%)$, as shown in Tables 2,3 , and 4 . 
254 Sustainable Development and Planning V

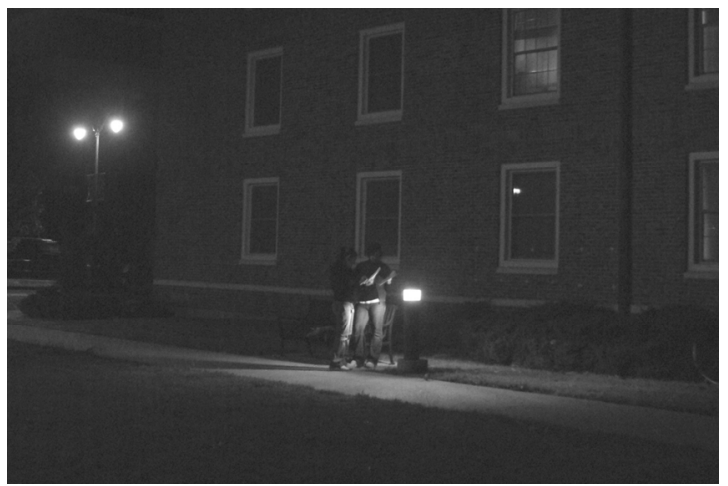

Figure 2: $\quad$ Non-cutoff fixtures create uplight effect.

Table 1: $\quad$ Housing site conditions and light fixtures.

\begin{tabular}{|c|c|c|c|c|c|c|c|c|}
\hline \multirow{2}{*}{ Site } & \multicolumn{3}{|c|}{$\begin{array}{c}\text { Sky Quality Reading } \\
\text { (mags/arcsecond2) }\end{array}$} & \multirow{2}{*}{ Cutoff } & \multicolumn{3}{|c|}{ Weather } & \multirow{2}{*}{ Moon Phase } \\
\cline { 2 - 3 } \cline { 6 - 7 } & Min & Max & Mean & & $\begin{array}{c}\text { Cloud } \\
\text { Cover }\end{array}$ & Precipitation & Temp ${ }^{\circ} \mathrm{F}\left({ }^{\circ} \mathrm{C}\right)$ & \\
\hline A & 15.4 & 17.5 & 16.3 & No & Clear & none & $65(18)$ & Waning Crescent $14 \%$ \\
\hline B & 15.6 & 16.1 & 15.7 & No & Clear & none & $69(21)$ & Waning Crescent $6 \%$ \\
\hline C & 16.1 & 18.0 & 16.4 & Yes & Clear & none & $73(23)$ & Waning Crescent $2 \%$ \\
\hline D & 10.8 & 10.8 & 10.8 & No & Clear & none & $55(13)$ & Waning Gibbous $87 \%$ \\
\hline E & 16.1 & 16.3 & 16.2 & Yes & $\begin{array}{c}\text { Mostly } \\
\text { Cloudy }\end{array}$ & none & $45(7)$ & Full $100 \%$ \\
\hline
\end{tabular}

Table 2: $\quad$ Lighting source identification.

\begin{tabular}{|c|c|c|c|c|c|c|c|c|c|c|c|c|}
\hline Site & \multicolumn{2}{|c|}{ Incandescent } & \multicolumn{2}{|c|}{ Fluorescent } & \multicolumn{2}{c|}{ Mercury } & \multicolumn{2}{c|}{ Metal Halide } & \multicolumn{2}{|c|}{ Sodium } & \multicolumn{2}{c|}{ Neon } \\
\hline & $\#$ & $\%$ & $\#$ & $\%$ & $\#$ & $\%$ & $\#$ & $\%$ & $\#$ & $\%$ & $\#$ & $\%$ \\
\hline A & 15 & 38.46 & 20 & 40.00 & 4 & 33.33 & 2 & 7.69 & 12 & 80.00 & 6 & 85.71 \\
\hline B & 2 & 5.13 & 8 & 16.00 & 0 & 0.00 & 4 & 15.38 & 2 & 13.33 & 1 & 14.29 \\
\hline C & 19 & 48.72 & 21 & 42.00 & 8 & 66.67 & 19 & 73.08 & 1 & 6.67 & 0 & 0.00 \\
\hline D & 2 & 5.13 & 0 & 0.00 & 0 & 0.00 & 0 & 0.00 & 0 & 0.00 & 0 & 0.00 \\
\hline E & 1 & 2.56 & 1 & 2.00 & 0 & 0.00 & 1 & 3.85 & 0 & 0.00 & 0 & 0.00 \\
\hline Total & 39 & 100.00 & 50 & 100.00 & 12 & 100.00 & 26 & 100.00 & 15 & 100.00 & 7 & 100.00 \\
\hline
\end{tabular}

Table 3: Lighting sources per site (All fixture types).

\begin{tabular}{|c|c|c|}
\hline Site & $\#$ & $\%$ \\
\hline A & 59 & 39.60 \\
\hline B & 17 & 11.41 \\
\hline C & 68 & 45.64 \\
\hline D & 2 & 1.34 \\
\hline E & 3 & 2.01 \\
\hline Total & 149 & 100.00 \\
\hline
\end{tabular}

Table 4: Lighting sources per type (All sites).

\begin{tabular}{|c|c|c|}
\hline Fixture Type & $\#$ & $\%$ \\
\hline Incandescent & 39 & 26.17 \\
\hline Fluorescent & 50 & 33.56 \\
\hline Mercury & 12 & 8.05 \\
\hline $\begin{array}{c}\text { Metal } \\
\text { Halide }\end{array}$ & 26 & 17.45 \\
\hline Sodium & 15 & 10.07 \\
\hline Neon & 7 & 4.70 \\
\hline Total & 149 & 100.00 \\
\hline
\end{tabular}


Artificial optical radiation was in evidence at all sites and ranged from a minimum of 0.0 horizontal fc $(0.0 \mathrm{~lx})$ to a maximum of 2.6 horizontal fc $(27.99$ $\mathrm{lx})$; and a minimum of 0.1 vertical fc $(1.1 \mathrm{~lx})$ to a maximum of 3.3 vertical $\mathrm{fc}$ (35.52 lx). Some measureable light levels were found on or near windows of housing units, including $1.3 \mathrm{fc}(14.0 \mathrm{~lx})$ at Site E. The vast majority of the housing sites were classified as having "dark surroundings" (Sites A, C, D and E). Only Site B was considered to have "bright surroundings." The sites' exterior building surfaces' reflectance values were examined and sites A, B, C, D and E were classified as "dark" with corresponding LRVs of 15, 16, 17, 16 and 19, as shown in Table 5.

For "floodlighting buildings and monuments" with dark surroundings and dark surfaces, the IESNA recommends an average of 5 vertical fc (50 1x). For bright surroundings the corresponding value is: $15 \mathrm{fc}(150 \mathrm{~lx})$ [38]. All sites' corresponding means fell well below these recommendations, fig 3 .

For security, the recommended average vertical illumination on building exteriors is 0.5 to $2 \mathrm{fc}(5$ to $20 \mathrm{~lx}$ ) [38]. The vertical mean measurements on the walls and windows of four of the sites fell within this range: A $(0.9 \mathrm{fc}, 9.7 \mathrm{~lx}) \mathrm{B}$ (1.3 fc, $13.9 \mathrm{~lx}), \mathrm{C}(1.1 \mathrm{fc}, 11.8 \mathrm{~lx})$ and E (1.2 fc, $19.4 \mathrm{~lx})$. Site D's mean (0.1 fc, $1.1 \mathrm{~lx}$ ) was below recommendations, fig 4 .

For safety, IESNA publishes recommendations for "hazards requiring visual detection" which are classified as either "slight" or "high" [38]. Due to the lack of critical obstacles observed at student housing sites, researchers classified all sites as slight. Within that category, IESNA also distinguishes between "low" or "high" normal activity levels. Based on observed activity, the researchers classified all sites as low. For "slight hazards requiring visual detection" at "low levels of normal activity" IESNA recommends $0.5 \mathrm{fc}(5.4 \mathrm{~lx})$. The mean horizontal measurements at Sites A (0.8 fc, $8.6 \mathrm{~lx}), \mathrm{B}(2.1 \mathrm{fc}, 22.6 \mathrm{~lx}), \mathrm{C}(1.9 \mathrm{fc}$, $20.5 \mathrm{~lx})$, and $\mathrm{E}(1.7 \mathrm{fc}, 18.6 \mathrm{~lx})$ exceeded these recommendations, while the mean at site $\mathrm{D}(0.4 \mathrm{fc}, 4.3 \mathrm{lux})$ fell below it, fig 5 .

UV radiation was also measured at regular intervals at the sites. All sites UV measurements were negligible, 0 microwatts $/ \mathrm{cm}^{2}$.

Table 5: Optical radiation levels, surroundings, and reflectances.

\begin{tabular}{|c|c|c|c|c|c|c|c|c|c|}
\hline \multirow{3}{*}{ Site } & \multicolumn{6}{|c|}{ Observations fc (lx) } & \multirow{3}{*}{ Surroundings } & \multirow{2}{*}{\multicolumn{2}{|c|}{$\begin{array}{c}\text { Vertical } \\
\text { Reflectance }\end{array}$}} \\
\hline & \multicolumn{3}{|c|}{ Horizontal } & \multicolumn{3}{|c|}{ Vertical } & & & \\
\hline & Min & Max & Mean & Min & Max & Mean & & LRV & Category \\
\hline $\mathrm{A}$ & $0.5(5.4)$ & $1.3(14.0)$ & $0.8(8.6)$ & $0.7(7.5)$ & $1.1(11.8)$ & $0.9(9.7)$ & Dark & 15 & Dark \\
\hline $\mathrm{B}$ & $1.9(20.5)$ & $2.3(24.8)$ & $2.1(22.6)$ & $0.9(9.7)$ & $2.0(21.5)$ & $1.3(13.9)$ & Bright & 16 & Dark \\
\hline $\mathrm{C}$ & $1.8(19.4)$ & $2.1(22.6)$ & $1.9(20.5)$ & $0.1(1.1)$ & $2.2(23.7)$ & $1.1(11.8)$ & Dark & 17 & Dark \\
\hline $\mathrm{D}$ & $0.0(0.0)$ & $2.2(23.7)$ & $0.4(4.3)$ & $0.1(1.1)$ & $0.3(11.8)$ & $0.1(1.1)$ & Dark & 16 & Dark \\
\hline$E$ & $1.0(10.8)$ & $2.6(27.99)$ & 1.7 (18.6) & $0.1(1.1)$ & $3.3(35.52)$ & $1.2(19.4)$ & Dark & 19 & Dark \\
\hline
\end{tabular}

\section{Limitations}

On the spectral distribution identification cards, the fluorescent category did not allow for the differentiation of CFLs from other types of fluorescent lighting. A 


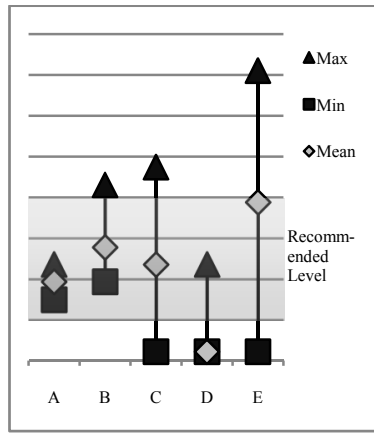

Figure 3: Security vertical light levels per site.

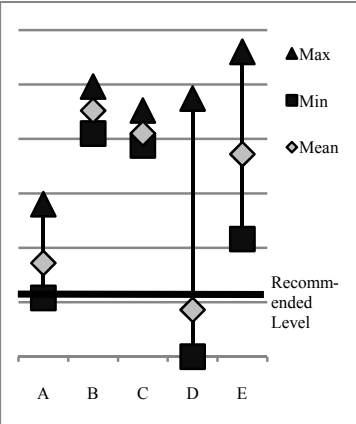

Figure 4: Safety horizontal light levels per site.

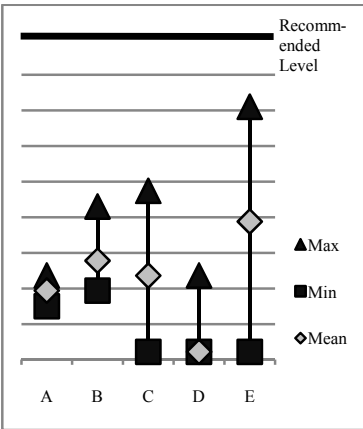

Figure 5: Floodlighting vertical light levels per site.

category for LEDs was not included on the cards. The study sites were not randomly selected and were limited in number and geographic area.

\section{Conclusion and discussion}

This study effectively engaged students in research efforts to measure the existing artificial optical radiation at student housing sites. It was concluded that this research successfully reached the participatory "citizen power" tier of the theoretical model described by Arnstein's "ladder of citizen participation".

The three hypotheses were partially or fully supported. Hypothesis 1: Artificial optical radiation levels at housing sites will exceed recommended levels was partially accepted. Sky quality was measured as fair to poor and is anticipated to obscure views of starry nights at the sites, while unshielded fixtures throw wasted light into the sky. Moon phases may have affected overall sky quality readings, especially for Sites D and E, which experienced $87 \%$ visible moon face and $100 \%$ visible moon face, respectively. The average visible light levels measured at some sites exceeded that recommended by the IESNA for safety. However, at some student housing sites, stakeholders may have created higher light levels in the cause of pedestrian safety. A non-cutoff "acorn" style fixture may have been an attempt to reinforce a nostalgic image. Universities should consider all relevant factors, including threats to circadian rhythms, when developing plans for artificial optical radiation at student housing sites.

Hypothesis 2: Non-sustainable light sources will be identified at student housing sites was accepted. Across student housing sites in the current study, non-sustainable incandescent lights were the second most utilized. These nonsustainable sources have low efficacy, are short-lived, and create the need for many bulbs to be relegated to landfills at their end-of-life. Fluorescents were identified as the source most often found at the sites. These have higher efficacy and longer life than incandescents. UV light emissions are a by-product of 
fluorescent light sources. However, the environmental impact of UV light at these sites was found to be negligible. This may be due to the lenses fitted to the fluorescents, which were apparently effective in shielding UV radiation. Vigilant maintenance of the lenses will be important for continued UV mitigation.

Hypothesis 3: Artificial optical radiation will be found on housing units' fenestration was accepted. The existing exterior lighting fixtures produced significant levels of light trespass onto the windows of occupied student rooms in the current study. These may disrupt circadian rhythms or cause other health problems for occupants. These are of concern, especially when one considers the vulnerable residents of these sites, college students. Stakeholders are encouraged to make informed choices regarding the selection, installation, and maintenance of sustainable lighting at student housing sites.

\section{Acknowledgements}

Although the research described in this article has been funded wholly or in part by the United States Environmental Protection Agency through grant/cooperative agreement SU834732 to Oklahoma State University, it has not been subjected to the Agency's required peer and policy review and therefore does not necessarily reflect the views of the Agency and no official endorsement should be inferred.

The author acknowledges the data collection contributions of the OSU students enrolled in DHM 4573 Environmental Sustainability Issues for Interior Designers, Sylvia Chaney, Dr. Gina Peek, and Abimola Asojo and her students.

\section{References}

[1] Consortium for Energy Efficiency. Residential Lighting Fact Sheet, http://www.cee1.org/resrc/facts/re-lt-fx.pdf

[2] Illuminating Engineering Society of North America (IESNA), Guideline for security lighting for people, property and public spaces, IESNA: New York, p. 37, 2003.

[3] International Dark-Sky Association (IDA). Glossary of basic terms, http://www.darksky.org/page/Glossary

[4] Illuminating Engineering Society of North America (IESNA). Light and human health: An overview of the impact of optical radiation of visual, circadian, neuroendocrine, and neurobehavioral responses, IESNA: New York, 2008.

[5] Burgess, H., Sharkey, K., \& Eastman, C., Bright light, dark and melatonin can promote circadian adaptation in night shift workers. Sleep Medicine Reviews, 6(5), pp. 407-420, 2002.

[6] Eastman, C., Stewart, K., Mahoney, M., \& Liu, L., Dark goggles and bright light improve circadian rhythm adaption to night-shift work. Sleep: Journal of Sleep Research \& Sleep Medicine, 17(6), pp. 535-543, 1994.

[7] Van Someren, E., Kessler, A., Mirmiran, M., \& Swaab, D., Indirect bright light improves circadian rest-activity rhythm disturbance in demented patients. Biological Psychiatry, 41(9), pp. 955-963, 1997. 
[8] Yamadera, H., Ito, T., Suzuki, H., Asayama, K., Ito, R., \& Endo, S., Effects of bright light on cognitive and sleep-wake (circadian) rhythm disturbances in Alzheimer-type dementia. Psychiatry \& Clinical Neurosciences, 54(3), pp. 352-353, 2000.

[9] Boyce, P.R., Lemmings, light, and health. Leukos: The Journal of the Illuminating Engineering Society, 2(3), pp. 24-31, 2006.

[10] Figueiro, M.G., Rea, M.S., \& Bullough, J.D., Does architectural lighting contribute to breast cancer? Journal of Carcinogenesis, 5(20), 2006.

[11] GLOBE at Night. Globe at night: Less of our light for more starlight, http://www.globeatnight.org/index.html

[12] Rich, C., \& Longcore, T., (eds.). Ecological Consequences of Artificial Night Lighting, Island Press: Washington DC, 2005.

[13] American Medical Association, Resolution 516(A-09): Advocating and support for light pollution control efforts and glare reduction for both public safety and energy savings, http://www.ama-assn.org/amal/pub/upload $/ \mathrm{mm} / 475 /$ refcome.pdf

[14] Swerdlow, A.J., English, J.S.C., MacKie, R.M., O’Doherty, C.J., Hunter, J.A.A., Clark, J., \& Hole, D.J., Fluorescent lights, ultraviolet lamps, and risk of cutaneous melanoma. British Medical Journal, 297, pp. 647-649, 1988, September 10.

[15] Scientific Committee on Emerging and Newly-Identified Health Risks (SCENIHR). Scientific opinion on light sensitivity, http://ec.europa.eu/ health/ph_risk/committees/04_scenihr/docs/scenihr_o_019.pdf

[16] Ham, W.T. . Ocular hazards of light sources: Review of current knowledge. Journal of Occupational Medicine, 25(2), pp. 101-103, 1983, February.

[17] Kitchel, E. Light and low vision, http://cclvi.org/contributions/light_and low vision.htm

[18] Kitchel, E. The effects of fluorescent light on the ocular health of persons with pre-existing eye pathologies, http://www.naasln.org/documents/ articles/kitchel_fluorescent light.pdf

[19] U.S. Environmental Protection Agency. EPA SunWise: Health Effects of UV Radiation, http://www.epa.gov/sunwise/uvandhealth2.html

[20] Freyssinier, J., Frering, D., Taylor, J., Narendran, N., \& Rizzio, P., Reducing lighting energy use in retail display windows. Sixth International Conference on Solid State Lighting Proceedings of SPIE 6337, 66371L, 2006.

[21] Summers, T., Hebert, P., Shedding some light on store atmospherics: Influence of illumination on consumer behavior. Journal of Business Research, 54(2), pp. 145-150, 2001.

[22] Areni, C., \& Kim, D., The influence of in-store lighting on consumers' examination of merchandise in a wine store. International Journal of Research Marketing, 11(2), pp. 117-125, 1994.

[23] Kalafatis, S., Pollard, M., East, R., \& Tsogas, M., Green marketing and Ajzens' theory of planned behaviour: A cross-market examination. The Journal of Consumer Marketing, 16(5), pp. 441-460, 1999. 
[24] Stall-Meadows, C., \& Hebert, P.R., The sustainable consumer: An in-situ study of residential lighting alternatives as influenced by in-field education. International Journal of Consumer Studies, 35, pp. 164-170, 2011.

[25] Rasmussen, T., Goepfrich, V., \& Horkitz, K. Drivers of CFL purchase behavior and satisfaction: What makes a consumer buy and keep buying? http://www.cee1.org/eval/db_pdf/758.pdf

[26] Chilcote, A., Guin, A., \& Kirby, S., Residential energy conservation: Program design for today's consumers. Proceedings of the 2007 Annual Conference of the Housing Education and Research Association.

[27] Bhusal, P., Zahnd, A., Eloholma, M., \& Halonen, L., Replacing fuel based lighting with light emitting diodes in developing countries: Energy and lighting in rural Nepali homes. Leukos, 3(4), pp. 277-291, 2007, April.

[28] Kumar, A., Jain, S., \& Bansal, N., Disseminating energy-efficient technologies: A case study of compact fluorescent lamps (CFLs) in India. Energy Policy, 31(3), pp.259-272, 2003, February.

[29] Kjaerulf, F., Transforming the CFL market by consumer campaigns. Right Light, 2, pp. 145-147, 1997.

[30] Peon, R., Doluweera, G., Platonova, I., Irvine-Halliday, D., \& IrvineHalliday, G., Solid state lighting for the developing world: The only solution. Optics and Photonics 2005, Proceedings of SPIE, 5941, pp. 109123, 2005.

[31] Reynolds, T., DeSisto, T., Murray, B., \& Kolodinsky, J., Promoting energy efficiency in small island states: Overcoming barriers to the adoption of compact fluorescent lighting in Saint Lucia. International Journal of Consumer Studies, 31(5), pp. 460-467, 2007.

[32] Hebert, P., Approach-avoidance behavior of consumers as influenced by existing and supplemental merchandise display lighting [Unpublished Doctoral Dissertation]. Louisiana State University: Baton Rouge, LA, 1997.

[33] Atiles, J., Wysocki, J. \& Tremblay, K., Energy Star: Introducing a new cooperative extension partnership. Journal of the Housing Education and Research Association, 30(1), pp. 59-68, 2003.

[34] Consortium for Energy Efficiency (CEE). CEE's residential lighting initiative, http://www.ceel.org/resid/rs-lt/rs-lt_init_descr.pdf

[35] Consortium for Energy Efficiency (CEE). CEE's residential lighting initiative, http://www.ceel.org/resid/rs-lt-main.php3

[36] Arnstein, S., A ladder of citizen participation. Journal of the American Institute of Planning, 35(4), pp. 216-224, 1969.

[37] Attardi, W., Educating the general public on lighting a good idea? Paper disseminated at the Illuminating Engineering Society of North America Centennial Conference, New York, NY, p. 3, 2006.

[38] Rea, M., (ed), The IESNA lighting handbook ( $9^{\text {th }}$ Edition). Illuminating Engineering Society of North America: New York, 2000.

[39] Walker, C., Bueter, C, Hurst, A., White, V. \& Patten, K. GLOBE at Night: using Sky Quality Meters to measure sky brightness, http://www.noao.edu/outreach/press/pr08/files/GaN_SQM.pdf 